\title{
Allogenic natural killer cell immunotherapy of sizeable ovarian cancer: A case report
}

\author{
SILUN XIE ${ }^{1}$, JIBING CHEN ${ }^{2}$, MINGJIIE ZHANG ${ }^{1}$ and ZHENGYI WU ${ }^{1}$ \\ ${ }^{1}$ Shenzhen Hank Bioengineering Institute, Shenzhen, Guangdong 518004; ${ }^{2}$ Cancer Institute of Fuda Cancer Hospital, \\ Jinan University School of Medicine, Guangzhou, Guangdong 510665, P.R. China
}

Received November 22, 2016; Accepted February 17, 2017

DOI: $10.3892 / \operatorname{mco} .2017 .1230$

\begin{abstract}
Masses are often detected in the abdomen of patients with sizeable ovarian cancer. There are currently no effective treatments available for late-stage ovarian cancer. Immunotherapy is gaining increasing attention worldwide in the clinical setting due to its ability to eliminate tumor cells and its favorable toxicity profile. We herein report the case of a 60-year-old woman who received allogenic natural killer (NK) cell immunotherapy for a sizeable ovarian carcinoma and achieved a noteworthy response. NK cells were isolated from the patient's own peripheral blood mononuclear cells, and the cell numbers were increased to 8-10 billion. The activated cells were expanded ex vivo for 14 days prior to intravenous infusion. After six infusions of NK cell therapy $>3$ months, the level of carbohydrate antigen 125 decreased significantly (from 11,270 to $580 \mathrm{U} / \mathrm{ml}$ ). Furthermore, the size of the masses in the abdomen was markedly reduced. Overall, the treatment had few adverse effects and it prolonged patient survival. The present data and the patient response suggest that allogenic NK cell immunotherapy is a promising approach for ovarian cancer, with few treatment-related adverse effects. The patient received six intravenous infusions of allogenic HANK cells between March, 2015 and June, 2015, but discontinued in October, 2015 and succumbed to the disease in March, 2016 following relapse.
\end{abstract}

\section{Introduction}

Due to the position of the pelvis, the early symptoms of ovarian cancer may not be noticed, with $60-70 \%$ of the patients being diagnosed at later stages of the disease. Chemotherapy is effective in $\sim 80 \%$ of patients with ovarian cancer; however, $>60 \%$ of the patients relapse, and the 5-year survival rate is $<40 \%$ (1).

Correspondence to: Dr Mingjie Zhang, Shenzhen Hank Bioengineering Institute, Building 119-5F, Liantang 1st Industrial Park, 72 Guowei Road, Shenzhen, Guangdong 518004, P.R. China E-mail: ming.zhang@hankbio.org

Key words: allogenic immunotherapy, high activity natural killer cells, high quanity natural killer cells, high purity natural killer cells, ovarian cancer, massive ascites
Patients with ovarian cancer often display large abdominal masses in the later stages of the disease, which are mostly cystic or solid, and there are currently no effective treatments available. Adoptive immunotherapy is aimed at destroying tumor cells and it is based on a theory that the host immune system may generate an immune response against cancer cells. Natural killer (NK) cells in the human immune system play an important role in anticancer treatment. NK cells perform immunosurveillance mediated by the 'missing-self' mechanism, i.e., NK cell inhibitory receptor signaling is decreased when the expression of the major histocompatibility complex-I molecules on the target cell is downregulated or missing (2). In addition, the intracellular signaling pathways in NK cells are activated. Mediated by perforin and granzyme B, the target cell is lysed. Consequently, donor NK cells are alloreactive towards recipient cells that lack their inhibitory receptor ligands. It is advisable that testing for killer cell inhibitory receptor (KIR) and its ligand, human leukocyte antigen class I, be performed prior to NK cell cultivation.

The aim of the present study was to report the results of six infusions of immune cell therapy in a 60-year-old patient with a sizeable ovarian carcinoma.

\section{Case report}

Patient history. A 60-year-old woman was diagnosed with ovarian carcinoma at the Guangdong General Hospital (Guangzhou, Guangdong) in March, 2015. The patient had massive ascites and was unable to eat or walk. The expected survival was $\leq 1$ month. To improve the quality of life, the patient received allogenic NK cell immunotherapy.

Immunotherapy. Clinical-grade NK cells were cultured using clinical-grade reagents and under good manufacturing practice conditions. The human high activity NK cell in vitro preparation kit was used (Hank Bioengineering Co. Ltd, Shenzhen, China) that contained chimeric active cellular factors on K562 cell membranes (3), plasma treatment fluid, lymphocyte culture fluid additives, serum-free medium additives and cell infusion additives. This kit is intended for expanding and activating NK cells in peripheral blood mononuclear cells in vitro to prepare NK cells of higher quantity, purity and activity, namely highly activated NK (HANK) cells (4). Blood samples from the patient and donors were analyzed using the TIANamp Blood 
DNA kit (Tiangen Biotech Co., Ltd., Beijing, China) and KIR/ HLA-C allotypes Genotyping Low Resolution kit (Tianjin Super Biotechnology Developing Co., Ltd., Tianjin, China). Approximately 8-10 billion HANK cells may be harvested after culture from $80 \mathrm{ml}$ of peripheral blood using NK cell serumfree medium and culture bags (Tianjin Haoyang Biological Manufacture Co., Ltd, Tianjin, China). Cell counting and quality control inspection are commonly performed on day 12 of culture, and the quality indicators include $\geq 8$ billion total cells with $\geq 90 \%$ living cells, $\geq 85 \%$ CD3-/CD56+ cells (3), $\leq 1 \mathrm{EU} / \mathrm{ml}$ endotoxin, $\geq 80 \%$ cell killing activity against K562 target cells (3), and bacteria-, fungi- and mycoplasma-negative culture. After a 14-day culture, the HANK cells were divided into three parts and infused intravenously on days 15-17.

Detection of tumor markers. The level of carbohydrate antigen 125 (CA125, reference range $<30 \mathrm{U} / \mathrm{ml}$ ) expression was determined by radioimmunoassay. The tests were performed according to the protocols in the instruction manuals.

\section{Discussion}

In this study, we evaluated the efficacy and safety of allogenic NK cell immunotherapy in a patient with ovarian cancer. Polymerase chain reaction testing using sequence-specific primer by the abovementioned KIR-HLA genotyping kit revealed that the patient's KIRs were mismatched with her own HLA. The patient was treated with one infusion every 2 weeks over 3 months (between March, 31 and June, 11) and achieved a definitive improvement (Fig. 1). Computed tomography scans indicated that the abdominal mases were markedly reduced following NK cell infusion (Fig. 2). The expression levels of the ovarian cancer marker CA125 were measured after each HANK cell infusion (Fig. 3) and were found to have decreased from 11,270 to $580 \mathrm{U} / \mathrm{ml}$ after four infusions. The symptom of ascites was also alleviated during the immunotherapy. The number of overall leukocytes and neutrophils also improved with HANK cell infusion (Fig. 4).

In 1985, Rosenberg et al from the US National Cancer Institute were the first to apply lymphokine-activated killer cells to the treatment of melanoma (5). An increasing number of studies support the hypothesis that immunotherapy is one of the best cancer therapies in the clinical setting. NK lymphocytes are an important part of the innate immune system, as they are able to destroy tumor cells and target cells without antigens or sensitization. At the same time, NK cells secrete numerous cytokines, such as interferon (IFN) $-\gamma$ and tumor necrosis factor (TNF)- $\alpha$.

The pathogenesis of ovarian cancer has not been fully elucidated. The majority of the patients are already at an advanced stage of the disease when they receive treatment, and advanced disease is the leading cause of death in patients with gynecological tumors. Therefore, a more effective treatment is urgently required. With the development of tumor immunology and molecular biology, the use of tumor immunotherapy has increased significantly in clinical practice. Allogenic NK cell immunotherapy involves the intravenous infusion of immune cells that have been expanded and activated ex vivo, treating tumors by directly killing the tumor cells or stimulating the patient's immune response.

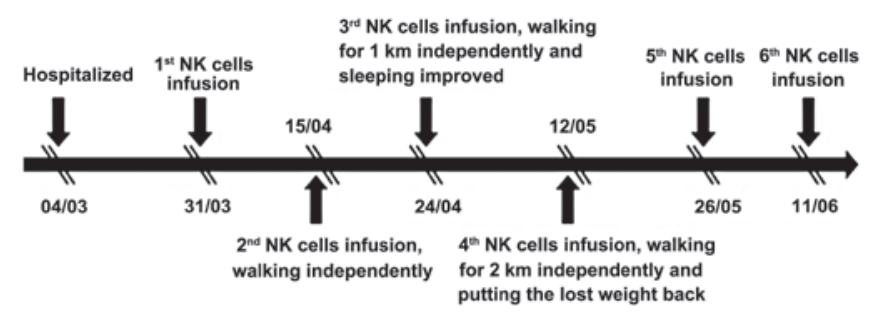

Figure 1. Treatment procedure with natural killer (NK) cell infusion.

Immunosuppression is observed in patients with ovarian cancer. The prognosis is closely associated with the patient's immune status, and ovarian cancer may significantly reduce the number of $\mathrm{B}$ cells, $\mathrm{CD} 4^{+} \mathrm{T}$ cells and follicular dendritic cells (6). A study including 176 patients with advanced ovarian cancer found T-lymphocyte invasion of the tumor in 50\% of the patients, and the number of $\mathrm{T}$ cells in the tumor was strongly associated with prolonged disease remission and improved overall survival rate (7). In a study of 117 epithelial ovarian cancer cases, T-lymphocyte immunohistochemical analysis revealed high numbers of intraepithelial CD8+ T cells in patients with long-term survival (8). Liu et al reported the curative effect of cytokine-induced killer cell treatment after surgery and chemotherapy for epithelial ovarian cancer. Compared with the control group, patients treated with immunotherapy exhibited a longer progression-free survival (9). These results encourage more attempts focused on immune anticancer therapy.

NK cells are large granular lymphocytes of the innate immune system responsible for elimination of infected cells. Based on the balanced recognition of membrane molecules by activating and inhibitory receptors expressed on the NK cell, NK cell-mediated cytotoxicity is directed towards target cells (10). The mechanism underlying destruction is multimodal and includes: Release of granzymes and perforin; apoptosis of target cells by the expression of the Fas ligand and TNF-related apoptosis-inducing ligand mediated by NK cells (11); promoting immune response by secreting cytokines such as IFN- $\gamma$, TNF- $\alpha$ and granulocyte-macrophage colony-stimulating factor (12). The level of NK cell response depends on the balance between signals from activating and inhibitory receptors (13).

Antibody-dependent cell-mediated cytotoxicity is an important antitumor mechanism of the immune system. Mediated by tumor-specific monoclonal antibodies (mAbs), the $\mathrm{Fc}$ regions of the mAbs bind to the antigens on the tumor cell surface, creating multiple interactions of $\mathrm{Fc}-\mathrm{Fc}$ receptors. Through the immunoreceptor tyrosine-based activation motif, cytotoxicity and the destruction of the tumor cell are triggered by downstream signaling $(14,15)$. It was demonstrated that overall and disease-free survival may be prolonged by the combination of the tumor-targeted $\mathrm{mAb}$ rituximab and NK cells for the treatment of non-Hodgkin lymphoma (16).

Over the past decade, adoptive transfer of allogenic NK cells has shown promise as an immunotherapy method. Taking advantage of alloreactivity by the 'missing-self' concept, a number of studies have demonstrated that infusion of haploidentical NK cells to exploit KIR/HLA alloactivity is safe and may achieve a better clinical effect in acute myelocytic 

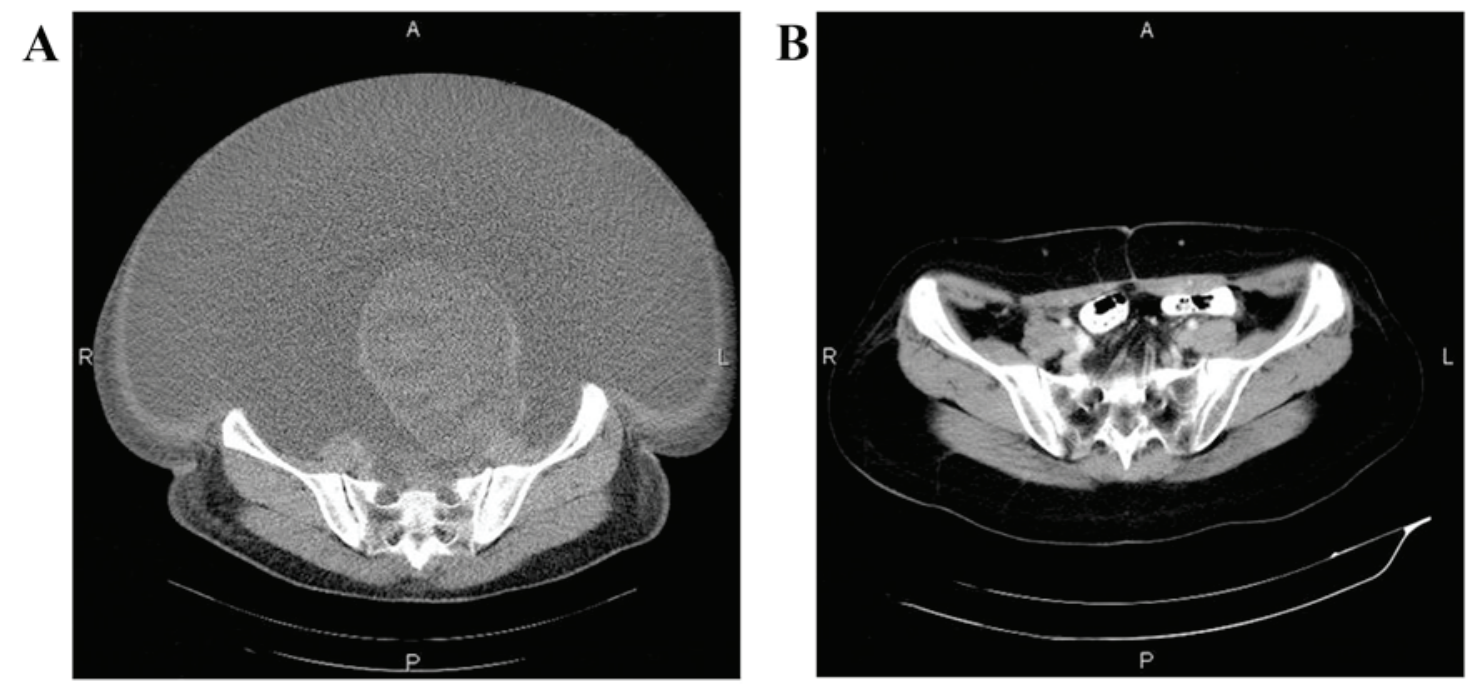

Figure 2. Computed tomography scans showing regression of the lesion following natural killer cell infusions. Lesion (A) prior to treatment and (B) after the sixth infusion.

leukemia (AML) patients (17-19). Among 19 AML patients, 5 achieved complete remission via subcutaneous interleukin-2 following haploidentical NK cell infusion. Without eliciting graft-versus-host disease, infusion of KIR-HLA mismatched donor NK cells may have enhanced the antitumor effect in the 5 AML patients (17). NK cell-based immunotherapies are also a promising treatment for solid tumors. In a phase II trial, patients with non-small-cell lung cancer received infusions of allogenic, in vitro activated NK cells, combined with chemotherapy, and the treatment was found to be safe and clinically effective (20). In addition, a phase II study of allogenic HANK cell therapy administered to 20 patients (14 with ovarian cancer and 6 with breast cancer) demonstrated that adoptive transfer of haploidentical NK cells following chemotherapy with lymphocyte depletion was clinically effective (21).

To the best of our knowledge, the treatment of ovarian cancer in the present report marks the first application of HANK cells to allogenic immunotherapy at the Fuda Cancer Hospital. Compared with traditional T-cell therapy, HANK cells exhibit the following characteristics (4): i) High activity. It is worth mentioning that the expression level of the activating receptor, which increased from the almost undetectable $0.31 \%$ to $65 \%$ after expansion, was enhanced by $\geq 200$-fold. ii) High quantity. The total number of CD56+ cells was increased $\sim 100$-fold. Ten billion NK cells rapidly proliferated in 2 weeks. iii) High purity. The purity of NK cells may reach $80 \%$, or even $\geq 96 \%$.

Our patient received six intravenous infusions of allogenic HANK cells between March, 2015 and June, 2015, but discontinued treatment due to financial difficulties in October, 2015; she succumbed to the disease in March, 2016 following relapse.

In conclusion, in the context of immune therapy, HANK cells may be beneficial for cancer patients by enhancing their cytotoxic lymphocytes. Allogenic HANK cell therapy was found to achieve long-term partial response and to remarkably improve the quality of life, and may be recommended for patients who have no other treatment options. Although allogenic HANK cell therapy shows promise as a cancer treatment, more studies are warranted to obtain more clinical data.

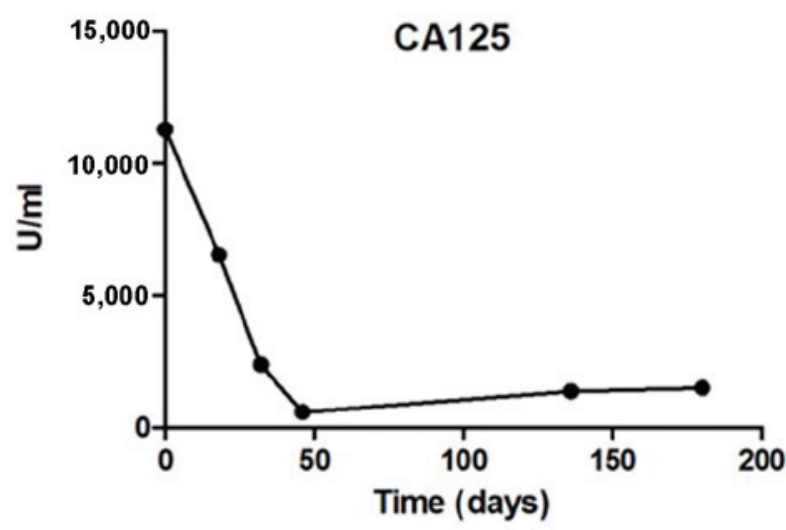

Figure 3. Carbohydrate antigen (CA)125 expression levels were evaluated at $0,18,32,46,136$ and 180 days after natural killer cell therapy.

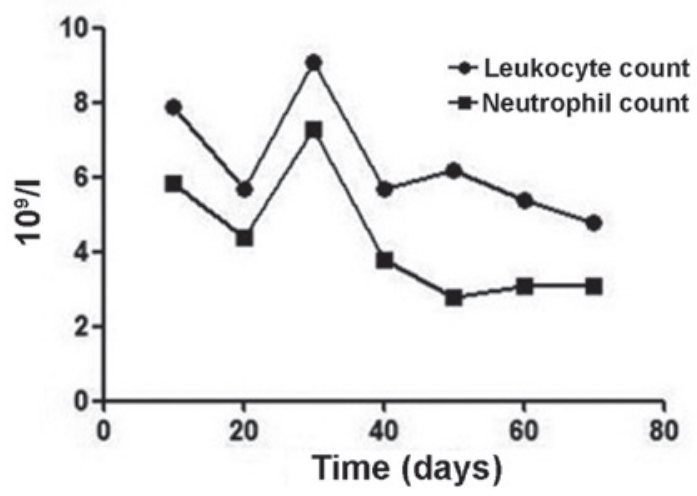

Figure 4. Leukocyte count and neutrophil count at 10, 20, 30, 40, 50, 60 and 70 days after natural killer cell therapy.

\section{Acknowledgements}

The present study was supported by the International Scientific Fund of Fuda Cancer Hospital, Guangzhou (Y2016-ZD-001). 


\section{References}

1. Siegel R, Naishadham D and Jemal A: Cancer statistics, 2012. CA Cancer J Clin 62: 10-29, 2012.

2. zum Büschenfelde CM, Hermann C, Schmidt B, Peschel C and Bernhard H: Antihuman epidermal growth factor receptor 2 (HER2) monoclonal antibody trastuzumab enhances cytolytic activity of class I-restricted HER2-specific T lymphocytes against HER 2-overexpressing tumor cells. Cancer Res 62: 2244-2247, 2002.

3. Imai C, Iwamoto S and Campana D: Genetic modification of primary natural killer cells overcomes inhibitory signals and induces specific killing of leukemic cells. Blood 106: 376-383, 2005.

4. Zhang M, Daniel S, Huang Y, Chancey C, Huang Q, Lei YF, Grinev A, Mostowski H, Rios M and Dayton A: Anti-West Nile virus activity of in vitro expanded human primary natural killer cells. BMC Immunol 11: 3, 2010.

5. Rosenberg SA, Lotze MT, Muul LM, Leitman S, Chang AE, Ettinghausen SE, Matory YL, Skibber JM, Shiloni E, Vetto JT, et al: Observations on the systemic administration of autologous lymphokine-activated killer cells and recombinant interleukin-2 to patients with metastatic cancer. N Engl J Med 313: 1485-1492, 1985.

6. Hoechst B, Ormandy LA, Ballmaier M, Lehner F, Krüger C, Manns MP, Greten TF and Korangy F: A new population of myeloid-derived suppressor cells in hepatocellular carcinoma patients induces CD4(+)CD25(+)Foxp3(+) T cells Gastroenterology 135: 234-243, 2008.

7. Zhang L, Conejo-Garcia JR, Katsaros D, Gimotty PA, Massobrio M, Regnani G, Makrigiannakis A, Gray H, Schlienger $\mathrm{K}$, Liebman MN, et al: Intratumoral $\mathrm{T}$ cells, recurrence, and survival in epithelial ovarian cancer. $\mathrm{N}$ Engl J Med 348: 203-213, 2003.

8. Sato E, Olson SH, Ahn J, Bundy B, Nishikawa H, Qian F, Jungbluth AA, Frosina D, Gnjatic S, Ambrosone C, et al: Intraepithelial $\mathrm{CD}^{+}$tumor-infiltrating lymphocytes and a high $\mathrm{CD}^{+} /$regulatory $\mathrm{T}$ cell ratio are associated with favorable prognosis in ovarian cancer. Proc Natl Acad Sci USA 102 18538-18543, 2005.

9. Liu J, Li H, Cao S, Zhang X, Yu J, Qi J, An X, Yu W, Ren X and Hao X: Maintenance therapy with autologous cytokine-induced killer cells in patients with advanced epithelial ovarian cancer after first-line treatment. J Immunother 37: 115-122, 2014.

10. Orange JS: Formation and function of the lytic NK-cell immunological synapse. Nat Rev Immunol 8: 713-725, 2008.

11. Zompi S and Colucci F: Anatomy of a murder--signal transduction pathways leading to activation of natural killer cells Immunol Lett 97: 31-39, 2005.
12. Biron CA, Nguyen KB, Pien GC, Cousens LP and SalazarMather TP: Natural killer cells in antiviral defense: Function and regulation by innate cytokines. Annu Rev Immunol 17: 189-220, 1999.

13. Moretta L, Bottino C, Pende D, Vitale M, Mingari MC and Moretta A: Human natural killer cells: Molecular mechanisms controlling NK cell activation and tumor cell lysis. Immunol Lett 100: 7-13, 2005.

14. Ravetch JV and Bolland S: IgG Fc receptors. Annu Rev Immunol 19: 275-290, 2001.

15. Farag SS, VanDeusen JB, Fehniger TA and Caligiuri MA Biology and clinical impact of human natural killer cells. Int $\mathrm{J}$ Hematol 78: 7-17, 2003.

16. Alderson KL and Sondel PM: Clinical cancer therapy by NK cells via antibody-dependent cell-mediated cytotoxicity. J Biomed Biotechnol 2011: 379123, 2011.

17. Miller JS, Soignier Y, Panoskaltsis-Mortari A, McNearney SA, Yun GH, Fautsch SK, McKenna D, Le C, Defor TE, Burns LJ, et al: Successful adoptive transfer and in vivo expansion of human haploidentical NK cells in patients with cancer. Blood 105: 3051-3057, 2005.

18. Rubnitz JE, Inaba H, Ribeiro RC, Pounds S, Rooney B, Bell T, Pui CH and Leung W: NKAML: A pilot study to determine the safety and feasibility of haploidentical natural killer cell transplantation in childhood acute myeloid leukemia. J Clin Oncol 28: 955-959, 2010.

19. Curti A, Ruggeri L, D'Addio A, Bontadini A, Dan E, Motta MR, Trabanelli S, Giudice V, Urbani E, Martinelli G, et al: Successful transfer of alloreactive haploidentical KIR ligand-mismatched natural killer cells after infusion in elderly high risk acute myeloid leukemia patients. Blood 118: 3273-3279, 2011.

20. Iliopoulou EG, Kountourakis P, Karamouzis MV, Doufexis D, Ardavanis A, Baxevanis CN, Rigatos G, Papamichail M and Perez SA: A phase I trial of adoptive transfer of allogeneic natural killer cells in patients with advanced non-small cell lung cancer. Cancer Immunol Immunother 59: 1781-1789, 2010.

21. Geller MA, Cooley S, Judson PL, Ghebre R, Carson LF, Argenta PA, Jonson AL, Panoskaltsis-Mortari A, Curtsinger J, McKenna D, et al: A phase II study of allogeneic natural killer cell therapy to treat patients with recurrent ovarian and breast cancer. Cytotherapy 13: 98-107, 2011. 